\title{
Consumos e Digestibilidades Totais e Parciais de Matéria Seca, Matéria Orgânica, Proteína Bruta e Extrato Etéreo em Novilhos Submetidos a Três Níveis de Ingestão e Duas Metodologias de Coleta de Digestas Abomasal e Omasal ${ }^{1}$
}

\section{Maria Ignez Leão², Sebastião de Campos Valadares Filho², Luciana Navajas Rennó3 ${ }^{3}$ Lúcio Carlos Gonçalves ${ }^{4}$, Paulo Roberto Cecon ${ }^{2}$, José Augusto Gomes Azevedo, Rilene Ferreira Diniz Valadares ${ }^{6}$}

\begin{abstract}
RESUMO - Seis novilhos castrados, fistulados no rúmen e abomaso foram distribuídos em dois quadrados latinos 3x3 (três animais, três níveis de oferta - 1,5;2,0 e 2,5\% PV e três períodos) para comparar as técnicas de coleta de digestas abomasal e omasal, para determinação do fluxo de nutrientes, e avaliar o efeito dos três níveis de oferta sobre os consumos e as digestibilidades aparentes totais e parciais de MS, MO, PB e EE. Os fluxos de digesta e a excreção fecal foram estimados com óxido crômico. Os consumos de MS, MO, PB, EE e NDT apresentaram comportamento linear crescente, em função dos níveis de ingestão. O coeficiente de digestibilidade aparente total da MS diminuiu linearmente com o aumento da ingestão. A digestibilidade aparente da MS no rúmen não diferiu entre os tratamentos, apresentando média de 73,2\% para as equações conjuntas. A digestibilidade total da MO apresentou comportamento linear decrescente, em função dos níveis de ingestão, e as digestibilidades ruminal e intestinal total não foram afetadas pelos tratamentos, com médias de 81,6 e 18,4\%, respectivamente, para as equações conjuntas. O teste de identidade de modelos indicou diferenças entre as digestibilidades totais da PB obtidas nas diferentes metodologias. Quando se compararam as digestões no rúmen e nos intestinos, não se constatou diferença entre as metodologias. A digestibilidade total do EE não foi influenciada pelos tratamentos e apresentou valor médio de 76,3\%. As digestibilidades ruminal e intestinal total do EE apresentaram comportamento linear crescente e decrescente, respectivamente, em função dos níveis de ingestão. A coleta de digesta omasal, via fístula ruminal, pode ser usada para substituir a coleta de digesta abomasal, não sendo necessária, portanto, a fistulação no abomaso, tornando o estudo dos locais de digestão um processo menos invasivo. O teor de NDT diminui com o aumento do nível de oferta de alimento.
\end{abstract}

Palavras-chave: novilhos, consumo, digestibilidade, coleta digesta omasal, coleta digesta abomasal

\section{Intake and Total and Partial Digestibility of Dry Matter, Organic Matter, Crude Protein and Ether Extract of Steers under Three Offer Levels and Two Collection Methodologies of Abomasal and Omasal Digesta}

\begin{abstract}
Six castrated steers fistulated in the rumen and abomasum were randomly assigned to two 3 x 3 Latin squares (three animals, three intake levels [1.5 supply, 2.0 and $2.5 \% \mathrm{LW}$ ] and three periods) to compare the collection techniques for abomasal and omasal digesta in order to determine the flow as well as to evaluate the effects of the three offer levels $(1.5 ; 2.0$ and $2.5 \%$ live weight $)$ on both intakes and total and partial apparent digestibilities of DM, OM, CP, EE and TDN. The chromic oxide was used to estimate the digesta flows and the fecal excretion. DM, OM, CP, EE and TDN intakes showed an increasing linear behavior, according to the ingestion levels. DM total apparent digestibility coefficient decreased linearly, as ingestion levels increased. DM apparent digestibility in the rumen did not differ among treatments and averaged $73.2 \%$ for the overall equations. OM total digestibility showed decreasing linear behavior, according to the ingestion levels, whereas the ruminal and total intestinal digestibilities were not affected by the treatments (average of 81.6 and $18.4 \%$ for the overall equations, respectively). The model identity test showed some differences among the CP total digestibilities obtained by different methodologies were observed. When ruminal and intestinal digestions were compared, no differences among both methodologies were observed. EE total digestibility was not affected by the treatments, with average value of $76.3 \%$. EE total ruminal and intestinal digestibilities exhibited both increasing and decreasing linear behaviors, respectively, as a function of the ingestion levels, showing an average value of 76.3\%. EE total ruminal and intestinal digestibilities showed both increasing and decreasing linear behaviors, respectively, as a function of the ingestion levels. Omasal digesta collection, through ruminal fistula, can be used to replace abomasum fistula, becoming the study of digestion locals a less invasive process. TDN content decreased as feed offer levels increased.
\end{abstract}

Key Words: steers, ingestion, digestibility, omasal digesta collection, abomasal digesta collection

\footnotetext{
1 Parte da tese de Doutorado apresentada à UFMG.

2 Professor do DZO/UFV (mileao@ufv.br)

3 Professora da UNIPAC - Juiz de Fora, MG.

4 Professor da UFMG.

5 Professor da UESC.

6 Professor do DVT/UFV.
} 


\section{Introdução}

A determinação do consumo de matéria seca (MS) é fundamental na nutrição animal, porque estabelece as quantidades de nutrientes disponíveis para a saúde e produção dos animais. Adequada estimativa do consumo é importante para a formulação de dietas, pois previne a super ou subalimentação e favorece a eficiente utilização de nutrientes. A subalimentação limita a produção e pode afetar o estado fisiológico do animal, ao passo que a superalimentação eleva os custos com a alimentação, e quantidades elevadas de determinados nutrientes causam efeitos prejudiciais à saúde do animal. $\mathrm{O}$ consumo de MS é função da duração do período e da frequiência de alimentação, determinadas pelo animal e por fatores dietéticos que afetam a fome e a saciedade (Mertens, 1994).

Existe uma relação positiva entre a digestibilidade das forragens e o nível de consumo, em função da limitação física. Aumento da taxa de degradação e/ou do fluxo de digesta do rúmen eleva o consumo. Em ruminantes sob dietas com alto teor de energia, que são digeridas rapidamente, este limite físico não é atingido, e o animal controla o consumo para satisfazer suas exigências em energia. Para atingir o nível requerido de produção, é necessária a suplementação da forragem com concentrado, que deprime o consumo, de acordo com o nível de concentrado e a qualidade da forragem e do concentrado (Forbes, 1995).

Conrad et al. (1964) sugeriram que o enchimento físico é limitante ao consumo de MS de dietas com digestibilidade abaixo de $66 \%$ e que controles metabólicos limitam o consumo de dietas com digestibilidade superior a este valor.

Sniffen et al. (1993) e Mertens (1994) atribuíram o controle da ingestão de alimentos a três mecanismos básicos: o fisiológico, que é regulado pelo balanço nutricional da dieta, especificamente relacionado à manutenção do equilíbrio energético; o físico, que está associado à capacidade de distensão do rúmenretículo e ao teor de fibra em detergente neutro (FDN) da ração; e a regulação psicogênica, relacionada à resposta do animal a fatores inibidores ou estimuladores no alimento ou manejo alimentar.

Digestibilidade ruminal é o produto do tempo de retenção no rúmen pelas características de degradação do alimento. As partículas maiores e menos densas dos alimentos permanecem por mais tempo no rúmen, fazendo com que seja digerido em sua máxima extensão possível, ou seja, seu potencial de digestibilidade. No entanto, fatores como níveis de alimentação e capacidade do rúmen causam variações no tempo de permanência do alimento neste compartimento e, portanto, em sua digestibilidade. Aumento na taxa de passagem pela moagem do alimento acarreta maior consumo, mas a digestibilidade é reduzida, em função do menor tempo no trato digestivo (Forbes, 1995).

Jonhson \& Berger (1982), citados por Merchen et al. (1986), em trabalho de revisão, indicaram que o aumento no nível de consumo comumente resulta em decréscimo na proporção de matéria orgânica (MO) aparentemente digerida no rúmen.

Em novilhos Hereford submetidos a dois níveis de consumo (9,1 e 6,1 kg de MS/dia), as digestibilidades ruminais aparentes de $\mathrm{MO}$ e FDN e a digestibilidade total da FDN foram mais baixas nos animais submetidos a níveis altos de consumo em relação aos baixos níveis: 41,3 x 44,3\%; 56,0 x $60,2 \%$ e 64,3 x 68,7\%; respectivamente (Firkins et al., 1986).

Segundo Van Soest (1994), as condições ecológicas do rúmen devem ser mantidas dentro de limites que permitam a normalidade do metabolismo e do crescimento microbiano.

A digestão da matéria orgânica e a degradação do nitrogênio do alimento no rúmen ocorrem por um processo relativamente contínuo. Conseqüentemente, o tempo de retenção ou de exposição dos nutrientes no rúmen, para o processo de degradação, influencia a quantidade dos nutrientes não-degradados no rúmen. Várias pesquisas têm sugerido que a estimativa da fração não-degradada no rúmen pode ser maior em nível de consumo mais alto, mas a magnitude da resposta não tem sido definida (Zinn \& Owens, 1983).

Aumentos no consumo proporcionam maior escape de nitrogênio microbiano e dietético para o duodeno, possivelmente, em virtude de maiores taxas de passagem (Van Soest, 1994).

A digestibilidade de dietas para vacas de leite é reduzida com o aumento da ingestão de alimentos (Tyrrel \& Moe, 1975). A taxa de redução na digestibilidade, associada ao nível de ingestão, está relacionada com a digestão da dieta fornecida em nível de mantença. Em nível de mantença, dietas com alta digestibilidade apresentaram maior taxa de redução desta com alimentação ad libitum que aquelas com baixa digestibilidade (NRC, 2001). O NRC $(1985,1989)$ adotou redução constante de $4 \%$

R. Bras. Zootec., v.33, n.6, p.1604-1615, 2004 
no teor de nutrientes digestíveis totais (NDT), para aumento no consumo de uma vez a mantença, para ajustar os valores de energia. Considerou-se redução máxima no teor de NDT de $8 \%$ para um consumo de três vezes o nível de energia de mantença. A partir dessa relação, o NRC considerou que uma dieta de mantença contendo $75 \%$ de NDT na MS teria seu teor de NDT reduzido para $69 \%$, quando o consumo de energia fosse três vezes a mantença. As diferenças nas taxas de redução na digestibilidade, geralmente, são mínimas para dietas contendo teor de NDT para mantença menor ou igual a $60 \%$ (NRC, 2001).

O NRC (2001) considera que o aumento no consumo reduz a digestibilidade dos nutrientes. Assim, recomenda-se corrigir o teor de NDT obtido para mantença (NDTm), usando a equação: \% Redução. $=[$ NDTm - $[(0,18 \times$ NDTm -10,3) $\mathrm{x}$ ingestão)]/ NDTm.

As fistulações no abomaso e no intestino delgado, em bovinos, ovinos e caprinos, têm sido usadas há alguns anos no Brasil, para estudos de digestão parcial. As fistulações permitem o acesso ao lúmen do trato digestivo para coletas de digesta, infusão de nutrientes, além de medidas alternativas de estudos de digestibilidade, como o uso de sacos de náilon móveis.

De acordo com Titgemeyer (1997), a técnica mais utilizada para determinação do fluxo de digesta do rúmen é a implantação de cânula em T no abomaso ou duodeno. Existem poucos trabalhos na literatura, em que se determina o fluxo de digesta sem implantação de cânula pós-ruminal (Ahvenjärvi et al., 2000). Técnica para coleta de digesta omasal, para implantação de uma cânula reentrante omaso-abomasal, em ovinos, foi publicada por Ash (1962). A estimativa do fluxo de compostos nitrogenados do rúmen foi feita por Punia et al. (1988), que obtiveram amostras de digesta ruminal através do orifício retículo omasal via fístula ruminal, succionando a digesta com o uso de uma bomba a vácuo.

Rupp et al. (1994) mediram as taxas de desaparecimento de ácidos graxos e o fluxo de fluidos pelo abomaso de bovinos usando uma técnica de canulação omasal. Um processo de amostragem de coleta omasal foi desenvolvido por Huhtanen et al. (1997), que mantiveram o dispositivo de coleta inserido dentro do omaso, durante 21 dias (período de coleta).

Amostragem omasal apresenta maiores vantagens que a coleta no abomaso ou no duodeno, principalmente por ser uma técnica menos invasiva.
Objetivou-se, com este trabalho, determinar os consumos e as digestibilidades totais e parciais da matéria seca (MS), matéria orgânica (MO), proteína bruta (PB) e extrato etéreo (EE), em novilhos submetidos a três níveis de ingestão e duas metodologias de coleta de digestas abomasal e omasal.

\section{Material e Métodos}

O experimento foi conduzido no Departamento de Zootecnia do Centro de Ciências Agrárias da Universidade Federal de Viçosa, em Viçosa, MG.

Foram utilizados seis novilhos $1 / 2$ sangue Holandês-Zebu, castrados, fistulados no rúmen e abomaso, com peso vivo médio inicial de $357,3 \mathrm{~kg}$, distribuídos em dois quadrados latinos $3 \times 3$, sendo três animais, três níveis de consumo (ofertas de 1,5; 2,0 e $2,5 \%$ peso vivo - PV em MS) e três períodos experimentais.

Os animais foram mantidos em baias individuais de alvenaria $(3 \times 3 \mathrm{~m})$, com pisos recobertos de borracha, cobertas e adaptadas com bebedouros automáticos e comedouros.

Os animais foram receberam uma dieta constituída de feno de capim-Tifton-85 (Cynodon spp.) e mistura concentrada (fubá de milho, farelo de trigo, farelo de soja, uréia e minerais), nas proporções de 60:40, formulada de acordo com o NRC (1996). As proporções dos ingredientes no concentrado estão na Tabela 1 e a composição química do concentrado, do feno e da ração total, na Tabela 2.

Cada um dos três períodos experimentais teve duração de 19 dias, sendo os sete iniciais para adaptação dos animais, seis para coleta de digesta abomasal e de fezes e seis para coleta de digesta omasal e de fezes.

A ração total foi fornecida uma única vez ao dia, às 7h30. A quantidade de ração para os animais submetidos à oferta de 2,5\% do PV foi calculada de modo a permitir 5 a $10 \%$ de sobras. Amostras de feno e de concentrado foram coletadas no início do experimento e imediatamente preparadas para posteriores análises laboratoriais. As sobras foram recolhidas todos os dias, antes de se distribuir a ração, e preparadas amostras compostas por animal em cada período. Além das sobras, foram recolhidas e feitas amostras compostas do feno e concentrado utilizados em cada período.

Para determinação das digestibilidades, utilizou-se o óxido crômico, introduzido no rúmen via fístula. A

\section{R. Bras. Zootec., v.33, n.6, p.1604-1615, 2004}


quantidade administrada foi de $15 \mathrm{~g}$, sempre 4 horas após o fornecimento da ração, a partir do 30 dia de adaptação até o último dia da coleta de digesta omasal.

As coletas de digesta de abomaso e de fezes foram realizadas em intervalos de 26 horas, iniciando-se às $8 \mathrm{~h}$ e, em seguida, às $10,12,14,16 \mathrm{e} 18 \mathrm{~h}$, perfazendo um total de seis amostras de abomaso, por animal em cada período. As coletas de omaso e de fezes foram feitas em dias alternados, utilizando-se três animais, sempre às 8,12 e $16 \mathrm{~h}$, perfazendo um total de três amostras por animal em cada período. Assim, os períodos de coletas de amostra de digesta de abomaso e fezes ou omaso e fezes foram de seis dias cada. Posteriormente, foram processadas em moinho com peneira de $1 \mathrm{~mm}$ de porosidade, preparando-se uma amostra composta com base no peso seco para cada animal, armazenada em frascos de vidro para análises laboratoriais.

Os teores de matéria seca (MS), matéria orgânica (MO), proteína bruta $(\mathrm{PB})$, extrato etéreo $(\mathrm{EE})$ e fibra em detergente neutro (FDN) foram quantificados conforme técnicas descritas por Silva (1990). As determinações do cromo foram feitas nas amostras

Tabela 1 - Composição percentual dos ingredientes utilizados no concentrado, na base da matéria natural

Table 1 - Percent composition of feedstuffs used in the concentrate (as fed basis)

\begin{tabular}{|c|c|}
\hline $\begin{array}{l}\text { Ingredientes } \\
\text { Feedstuffs }\end{array}$ & $\begin{array}{c}\text { Concentrado (\%) } \\
\text { Concentrate }\end{array}$ \\
\hline Fubá de milho & 48,60 \\
\hline Corn starch & \\
\hline Farelo de soja & 19,40 \\
\hline $\begin{array}{l}\text { Soybean meal } \\
\text { Farelo de trigo }\end{array}$ & 30,00 \\
\hline $\begin{array}{l}\text { Wheat middling } \\
\text { Uréia } \\
\text { Urea }\end{array}$ & 0,90 \\
\hline $\begin{array}{l}\text { Sulfato de amônia } \\
\text { Ammonia sulfate }\end{array}$ & 0,10 \\
\hline $\begin{array}{l}\text { Fosfato bicálcico } \\
\text { Dicalcium phosphate }\end{array}$ & 0,50 \\
\hline $\begin{array}{l}\text { Sal comum } \\
\text { Salt }\end{array}$ & 0,464 \\
\hline $\begin{array}{l}\text { Microminerais }{ }^{1} \\
\text { Minerals }\end{array}$ & 0,036 \\
\hline $\begin{array}{l}{ }^{1} \text { Composição percentu } \\
\text { cobre, 0,015; sulfato } \\
0,001 \text {; iodato de potá } \\
{ }^{1} \text { Percent composition: zin } \\
\text { sulfate, .001; sodium sel }\end{array}$ & $\begin{array}{l}\text { Co, } 0,018 \text {; sulfato de } \\
1 \text {; selenito de sódio, } \\
\text { ber sulfate, .015, cobalt } \\
\text { iodate, } .001 .\end{array}$ \\
\hline
\end{tabular}

R. Bras. Zootec., v.33, n.6, p.1604-1615, 2004 de abomaso, omaso e fezes, de acordo com o método proposto por Williams et al. (1962), citados por Silva (1990).

Para quantização dos carboidratos totais ( $\mathrm{CHO})$, utilizou-se a equação: 100 - (\%PB + \%EE + \% Cinzas). Os teores de carboidratos não-fibrosos (CNF) foram obtidos pela diferença entre os teores de $\mathrm{CHO}$ e FDN corrigida para cinzas e proteína (FDNcp).

Os teores de NDT foram calculados pela relação entre os consumos de NDT e de MS. Para o cálculo do consumo de NDT (cNDT), utilizou-se a fórmula descrita por Sniffen et al. (1992), cNDT $=(\mathrm{cPB}-$ $\mathrm{PBf})+2,25(\mathrm{cEE}-\mathrm{EEf})+(\mathrm{cCHO}-\mathrm{CHOf})$, em que $\mathrm{cPB}, \mathrm{cEE}$ e cCHO significam consumos de $\mathrm{PB}, \mathrm{EE}$ e $\mathrm{CHO}$, respectivamente, e $\mathrm{PBf}$, EEf e CHOf, teores de PB, EE e CHO nas fezes.

Os dados foram avaliados por análises de variância e de regressão, utilizando-se o programa SAEG Sistema de Análises Estatísticas e Genéticas (UFV, 1999). As comparações entre as equações de regressão dos parâmetros avaliados (consumo e digestibilidade) foram realizadas de acordo com a metodologia recomendada por Regazzi (1996), para testar a identidade de modelos.

Tabela 2 - Teores de matéria seca (MS), matéria orgânica (MO), proteína bruta (PB), extrato etéreo (EE), carboidratos totais (CHO), fibra detergente neutro (FDN) e carboidratos não-fibrosos (CNF) do concentrado, do feno e da ração

Table 2 - Contents of dry matter (DM), organic matter (OM), crude protein $(C P)$, ether extract $(E E)$, total carbohydrates (CHO), neutral detergent fiber (NDF) and nonfiber carbohydrates (NFC) of the concentrate, hay and ration

\begin{tabular}{|c|c|c|c|}
\hline $\begin{array}{l}\text { Itens } \\
\text { Items }\end{array}$ & $\begin{array}{c}\text { Concentrado } \\
\text { Concentrate }\end{array}$ & $\begin{array}{c}\text { Feno } \\
\text { Hay }\end{array}$ & $\begin{array}{l}\text { Ração } \\
\text { Ration }\end{array}$ \\
\hline $\operatorname{MS}(\%)$ & 84,65 & 88,16 & 86,76 \\
\hline $\begin{array}{l}D M \\
\mathrm{MO}^{1}\end{array}$ & 96,05 & 94,11 & 94,89 \\
\hline $\begin{array}{l}O M \\
\mathrm{~PB}^{1}\end{array}$ & 22,16 & 6,90 & 13,00 \\
\hline$C P$ & & & \\
\hline $\begin{array}{l}\mathrm{EE}^{1} \\
\mathrm{CHO}^{1}\end{array}$ & $\begin{array}{r}1,26 \\
78,73\end{array}$ & $\begin{array}{r}2,59 \\
85,42 \\
7675\end{array}$ & $\begin{array}{r}2,05 \\
82,74\end{array}$ \\
\hline $\begin{array}{l}\mathrm{FDN}^{1,2} \\
N D F\end{array}$ & 21,86 & 76,75 & 54,79 \\
\hline $\begin{array}{l}\mathrm{CNF}^{1} \\
N F C\end{array}$ & 56,87 & 8,67 & 27,65 \\
\hline
\end{tabular}




\section{Resultados e Discussão}

Na Tabela 3, são apresentados os consumos médios diários de MS, MO (kg/dia), PB e EE (g/dia), as equações de regressão (ER) e seus respectivos coeficientes de determinação, obtidos para os dias correspondentes a cada metodologia de coleta de digesta, no abomaso (ABO) e no omaso (OM), e para as duas metodologias em conjunto, em função dos níveis de oferta (NIV).

$\mathrm{O}$ teste de identidade de modelos, aplicado às equações de regressão para os consumos de MS, MO, PB e EE, em função dos níveis de ingestão, mostrou não haver diferenças entre as metodologias de coletas de digestas de abomaso e de omaso. Portanto, pode-se recomendar o uso da equação conjunta, que é comum aos consumos.

O consumo de MS teve comportamento linear crescente, em função dos níveis de ingestão, resultado esperado, em razão dos níveis de consumo prédeterminados em relação ao PV.

Os resultados indicam que a ingestão de MS foi, possivelmente, limitada pelo enchimento, nos animais que receberam 2,5\% PV, ou seja, ingestão ad libitum. Conrad et al. (1964) relataram que, em dietas com digestibilidade abaixo de $66 \%$, o consumo de MS é limitado pelo efeito de enchimento. No presente trabalho, a digestibilidade da MS observada para este nível foi de 64,9\% (Tabela 5).

Aumentos lineares nos consumos de MO, PB e EE podem ser atribuídos ao maior consumo de MS. Firkins et al. (1987) observaram que novilhos fistulados submetidos a dietas com $50 \%$ de volumoso e níveis de ingestão de 1,4 e 2,1\% PV consumiram 4,58 e $6,87 \mathrm{~kg} / \mathrm{dia}$ de $\mathrm{MO}$, respectivamente. No presente trabalho, nos níveis de 1,5 e 2,0\%, as ingestões de $\mathrm{MO}$ foram, em média, de 5,25 e 7,11 kg, respectivamente.

Os consumos médios diários de MS, MO, PB e $\mathrm{EE}(\% \mathrm{PV})$, as equações de regressão (ER) e os respectivos coeficientes de determinação, obtidos nos dias de coleta de digesta no abomaso (ABO) e omaso (OM), para as duas metodologias em conjunto, em função dos níveis de ingestão (NIV), são mostrados na Tabela 4. Não houve diferenças nos consumos entre as metodologias de coletas de digesta abomasal e omasal, conforme o teste de identidade de modelos.

Tabela 3 - Médias, equações de regressão (ER) e coeficientes de determinação $\left(r^{2}\right)$ para os consumos de matéria seca (MS), matéria orgânica (MO), em kg/dia, proteína bruta (PB) e extrato etéreo (EE), em g/dia, em função dos níveis de oferta (NIV), para as metodologias de coletas no abomaso ( $A B O)$ e no omaso (OM)

Table 3 - Means, regression equations (RE) and coefficients of determination $\left(r^{2}\right)$ for the intakes of dry matter (DM), organic matter (OM), $\mathrm{kg} /$ day, crude protein $(C P)$ and ether extract (EE), g/day, according to the offer levels (LEV), for the collection methodologies in the abomasum $(A B O)$ and omasum (OM)

\begin{tabular}{|c|c|c|c|c|c|}
\hline \multirow[t]{2}{*}{ Local } & \multicolumn{3}{|c|}{ NIV } & \multirow[t]{2}{*}{ ER } & \multirow[t]{2}{*}{$\mathrm{r}^{2}$} \\
\hline & 1,5 & 2,0 & 2,5 & & \\
\hline \multicolumn{6}{|c|}{ MS (kg/dia) } \\
\hline $\mathrm{ABO}$ & 5,53 & 7,49 & 8,13 & $\hat{Y}=2,6021+1,8486 \mathrm{X}$ & 0,92 \\
\hline $\mathrm{OM}$ & 5,53 & 7,49 & 8,07 & $\hat{Y}=2,5389+1,9544 \mathrm{X}$ & 0,91 \\
\hline Conjunto (Overall) & 5,53 & 7,49 & 8,10 & $\hat{Y}=2,5705+1,9015 \mathrm{X}$ & 0,91 \\
\hline \multicolumn{6}{|c|}{$\mathrm{MO}(\mathrm{kg} / \mathrm{dia})$} \\
\hline $\mathrm{ABO}$ & 5,25 & 7,11 & 7,72 & $\hat{Y}=2,4710+1,7503 \mathrm{X}$ & 0,92 \\
\hline $\mathrm{OM}$ & 5,25 & 7,11 & 7,66 & $\hat{Y}=2,4100+1,8519 \mathrm{X}$ & 0,91 \\
\hline Conjunto (Overall) & 5,25 & 7,11 & 7,69 & $\hat{Y}=2,4405+1,8011 \mathrm{X}$ & 0,91 \\
\hline \multicolumn{6}{|c|}{ PB (g/dia ) } \\
\hline $\mathrm{ABO}$ & 726,3 & 984,0 & 1105,0 & $\hat{Y}=0,3790+0,1806 \mathrm{X}$ & 0,96 \\
\hline $\mathrm{OM}$ & 726,3 & 984,0 & 1094,0 & $\hat{Y}=0,3675+0,1997 \mathrm{X}$ & 0,95 \\
\hline Conjunto (Overall) & 726,3 & 984,0 & 1099,5 & $\hat{Y}=0,3732+0,1901 \mathrm{X}$ & 0,95 \\
\hline \multicolumn{6}{|c|}{$\mathrm{EE}(\mathrm{g} / \mathrm{dia})$} \\
\hline $\mathrm{ABO}$ & 114,2 & 154,7 & 170,9 & $\hat{Y}=0,05677+0,03307 \mathrm{X}$ & 0,94 \\
\hline $\mathrm{OM}$ & 114,2 & 154,7 & 169,6 & $\hat{Y}=0,05542+0,03532 \mathrm{X}$ & 0,93 \\
\hline Conjunto (Overall) & 114,2 & 154,7 & 170,3 & $\hat{Y}=0,05609+0,03419 \mathrm{X}$ & 0,94 \\
\hline
\end{tabular}

\section{R. Bras. Zootec., v.33, n.6, p.1604-1615, 2004}


Portanto, recomenda-se o uso da equação conjunta, que é comum aos consumos.

Para os consumos de MS, MO, PB e EE (\% PV), o comportamento foi linear crescente, em função dos níveis de ingestão, resultado também já esperado, em função dos níveis pré-determinados de consumo.

Os consumos médios de MS de 2,07\%, no nível de oferta de $2,5 \%$, comprovaram que os animais nesta idade e deste grau de sangue não conseguiram consumir 2,5\% do PV. Segundo Silva (2001), o consumo de MS diminui com o aumento de PV dos animais. Assim, animais mais pesados apresentam menor consumo em relação ao PV. Considerando-se a equação $\mathrm{Y}=3,1237-0,0028 * \mathrm{PV}$ e o PV médio de $396,61 \mathrm{~kg}$ dos animais deste experimento, o consumo de MS esperado seria de $2,01 \%$. Vale ressaltar que esta equação foi obtida com bovinos Nelore.

O consumo médio de $1,91 \% \mathrm{PV}$, abaixo do valor pré-estabelecido de $2,0 \%$, é explicado pela variação no teor de MS dos ingredientes da ração.

Nos períodos 1,2 e 3 , a variação média de peso dos animais foi de 3,5; -3,5 e $2 \mathrm{~kg}$, respectivamente, para o nível de oferta de $1,5 \%$ PV. O consumo observado para os animais submetidos a este nível de oferta foi de $1,42 \% \mathrm{PV}$, suficiente para a mantença dos animais, que praticamente mantiveram seus pesos.

De acordo com a equação conjunta, observou-se maior consumo (aproximadamente $0,65 \%$ do PV) para cada $1 \%$ de aumento no nível de oferta da dieta.

Na Tabela 5, são apresentados os resultados das digestibilidades total (DMSTO), ruminal (DMSRU) e intestinal total (DMSIN) da MS, os teores de NDT, equações de regressão (ER) e os respectivos coeficientes de determinação, obtidos para as metodologias de coleta de digesta no abomaso (ABO) e no omaso $(\mathrm{OM})$ e para as duas metodologias em conjunto, em função dos níveis de ingestão (NIV). O teste de identidade de modelos, aplicado às equações de regressão para as digestibilidades total, ruminal e intestinal total da MS, em função dos níveis de ingestão, e para o teor de NDT, não indicou diferenças entre as metodologias de coleta de digesta de abomaso e de omaso. Portanto, recomenda-se o uso da equação conjunta, que é comum às duas metodologias.

O coeficiente de digestibilidade total da MS diminuiu linearmente com o aumento da ingestão. Van Soest (1994) relatou aumento na taxa de passagem em relação ao incremento do consumo, o que reduziu

Tabela 4 - Médias, equações de regressão (ER) e coeficientes de determinação $\left(r^{2}\right)$ para os consumos de matéria seca (MS), matéria orgânica (MO), proteína bruta (PB) e extrato etéreo (EE), em \% PV, em função dos níveis de oferta (NIV), para as metodologias de coletas no abomaso (ABO) e no omaso (OM)

Table 4 - Means, regression equations (RE) and coefficients of determination $\left(r^{2}\right)$ for the intakes of dry matter (DM), organic matter (OM), crude protein $(C P)$ and ether extract $(E E)$, in \%LW, according to the offer levels (LEV), for the collection methodologies in the abomasum (ABO) and omasum (OM)

\begin{tabular}{|c|c|c|c|c|c|}
\hline \multirow[t]{2}{*}{ Local } & \multicolumn{3}{|c|}{ NIV } & \multirow[t]{2}{*}{$\mathrm{ER}$} & \multirow[t]{2}{*}{$\mathrm{r}^{2}$} \\
\hline & 1,5 & 2,0 & 2,5 & & \\
\hline \multicolumn{6}{|c|}{$\mathrm{MS}(\% \mathrm{PV})$} \\
\hline $\mathrm{ABO}$ & 1,42 & 1,91 & 2,08 & $\hat{Y}=0,47919+0,662 \mathrm{X}$ & 0,93 \\
\hline $\mathrm{OM}$ & 1,42 & 1,91 & 2,06 & $\hat{Y}=0,51763+0,639 \mathrm{X}$ & 0,92 \\
\hline Conjunto (Overall) & 1,42 & 1,91 & 2,07 & $\hat{Y}=0,49841+0,6505 \mathrm{X}$ & 0,92 \\
\hline \multicolumn{6}{|c|}{$\mathrm{MO}(\% \mathrm{PV})$} \\
\hline $\mathrm{ABO}$ & 1,35 & 1,81 & 1,98 & $\hat{Y}=0,4531+0,62906 \mathrm{X}$ & 0,93 \\
\hline $\mathrm{OM}$ & 1,35 & 1,81 & 1,95 & $\hat{Y}=0,4915+0,606 \mathrm{X}$ & 0,92 \\
\hline Conjunto (Overall) & 1,35 & 1,81 & 1,97 & $\hat{Y}=0,4723+0,6175 \mathrm{X}$ & 0,92 \\
\hline \multicolumn{6}{|c|}{$\mathrm{PB}(\% \mathrm{PV})$} \\
\hline $\mathrm{ABO}$ & 0,187 & 0,25 & 0,282 & $\hat{Y}=0,04805+0,09586$ & 0,97 \\
\hline $\mathrm{OM}$ & 0,187 & 0,25 & 0,279 & $\hat{Y}=0,05434+0,09209 \mathrm{X}$ & 0,95 \\
\hline Conjunto (Overall) & 0,187 & 0,25 & 0,28 & $\hat{Y}=0,05119+0,09398 \mathrm{X}$ & 0,96 \\
\hline \multicolumn{6}{|c|}{$\mathrm{EE}(\% \mathrm{PV})$} \\
\hline $\mathrm{ABO}$ & 0,0293 & 0,0394 & 0,0438 & $\hat{Y}=0,008459+0,01452 \mathrm{X}$ & 0,95 \\
\hline $\mathrm{OM}$ & 0,0293 & 0,0394 & 0,0433 & $\hat{Y}=0,009414+0,01395 \mathrm{X}$ & 0,94 \\
\hline Conjunto (Overall) & 0,0293 & 0,0394 & 0,0436 & $\hat{Y}=0,008936+0,01424 \mathrm{X}$ & 0,95 \\
\hline
\end{tabular}

R. Bras. Zootec., v.33, n.6, p.1604-1615, 2004 
a digestibilidade - uma possível explicação para a redução na digestibilidade encontrada neste estudo. Llamas-Lamas \& Combs (1991), em revisão de literatura, afirmaram que a digestibilidade total é influenciada pelo nível de consumo. Esses autores, trabalhando com vacas consumindo 1,4 e 4 vezes o nível de mantença, em uma dieta com proporção volumoso: concentrado de $65: 35$, verificaram redução de 76,73 para 70,74\% na digestibilidade total da MS. Borges (2000), em estudo com novilhas alimentadas em nível de mantença e ad libitum, não encontrou diferenças nas digestibilidade da MS entre os tratamentos, com média de $61,0 \%$.

A digestibilidade de dietas para vacas de leite é reduzida com o aumento da ingestão de alimentos (Tyrrel \& Moe, 1975). A taxa de redução na digestibilidade, associada ao nível de alimentação, está relacionada com a digestão da dieta fornecida em nível de mantença.

Em experimento com novilhos que receberam diferentes níveis de proteína na ração, Valadares et al. (1997) obtiveram maior coeficiente de digestibilidade aparente total da MS para o teor de $14,5 \%$ de PB $(66,27 \%)$ que para os demais níveis de PB (7,0; 9,5 e 12\%), que não diferiram entre si, mostrando média de 59,25\%. Rennó (dados não publicados), trabalhando com novilhos submetidos a dietas com níveis crescentes de uréia $(0 ; 0,65 ; 1,3$ e $1,95 \% \mathrm{MS})$, não encontrou diferenças entre os tratamentos, para digestibilidade de MS com média de 70,55\%. Cardoso et al. (2000) descreveram digestibilidade média de $64,02 \%$, para diferentes níveis de concentrado na ração, enquanto Branco et al. (2001), de 69,3\%, com a inclusão de diferentes fontes protéicas na ração.

De acordo com a equação conjunta, houve redução de 2,027 unidades percentuais na digestibilidade da MS para cada $1 \%$ de aumento no nível de oferta. Ao comparar os valores médios, observa-se decréscimo de 66,9 para $64,9 \%$ na digestibilidade (redução percentual de 2\%). Avaliando a diminuição no teor de NDT com o nível de oferta, observa-se, em

Tabela 5 - Médias, equações de regressão $(E R)$ e coeficientes de determinação $\left(r^{2}\right)$ para as digestibilidades da matéria seca total (DMSTO), no rúmen (DMSRU) e nos intestinos (DMSIN) e para os teores de nutrientes digestíveis totais (NDT), em função dos níveis de oferta (NIV), para as metodologias de coletas no abomaso $(A B O)$ e no omaso (OM)

Table 5 - Means, regression equations (RE) and coefficients of determination $\left(r^{2}\right)$ for the total dry matter digestibilities (TODMD), in the rumen and in the intestines, and for the total digestible nutrients (TDN), according to the offer levels (LEV), for the collection methodologies in the abomasum $(A B O)$ and omasum $(O M)$

\begin{tabular}{|c|c|c|c|c|c|}
\hline \multirow[t]{2}{*}{ Local } & \multicolumn{3}{|c|}{ NIV } & \multirow[t]{2}{*}{$\mathrm{ER}$} & \multirow[t]{2}{*}{$\mathrm{r}^{2}$} \\
\hline & 1,5 & 2,0 & 2,5 & & \\
\hline \multicolumn{6}{|c|}{ DMSTO } \\
\hline $\mathrm{ABO}$ & 65,8 & 65,1 & 64,5 & $\hat{Y}=67,84-1,362 \mathrm{X}$ & 0,99 \\
\hline $\mathrm{OM}$ & 67,9 & 65,7 & 65,2 & $\hat{Y}=71,66-2,692 \mathrm{X}$ & 0,88 \\
\hline Conjunto (Overall) & 66,9 & 65,4 & 64,9 & $\hat{Y}=69,75-2,027 \mathrm{X}$ & 0,81 \\
\hline \multicolumn{6}{|c|}{ DMSRU $^{1}$} \\
\hline $\mathrm{ABO}$ & 73,1 & 73,6 & 73,7 & $\hat{Y}=73,5$ & \\
\hline $\mathrm{OM}$ & 72,9 & 72,9 & 73,1 & $\hat{Y}=73,0$ & \\
\hline Conjunto (Overall) & 73,0 & 73,3 & 73,4 & $\hat{Y}=73,2$ & \\
\hline \multicolumn{6}{|c|}{ DMSIN $^{1}$} \\
\hline $\mathrm{ABO}$ & 26,9 & 26,4 & 26,3 & $\hat{Y}=26,5$ & \\
\hline $\mathrm{OM}$ & 27,1 & 27,1 & 26,9 & $\hat{Y}=27,0$ & \\
\hline Conjunto (Overall) & 27,0 & 26,8 & 26,6 & $\hat{Y}=26,8$ & \\
\hline \multicolumn{6}{|c|}{ NDT $(\%)$} \\
\hline $\mathrm{ABO}$ & 63,66 & 62,10 & 62,70 & $\hat{Y}=64,7254-0,9537 \mathrm{X}$ & 0,37 \\
\hline $\mathrm{OM}$ & 67,90 & 63,75 & 64,10 & $\hat{Y}=70,7637-2,9061 \mathrm{X}$ & 0,66 \\
\hline Conjunto (Overall) & 65,33 & 62,93 & 63,40 & $\hat{Y}=67,7445-1,9299 \mathrm{X}$ & 0,49 \\
\hline
\end{tabular}

$1 \%$ do total digerível (\% total digestible). 
média, redução de, aproximadamente, $2 \%(65,33$ para $63,40 \%$ ), quando o nível de oferta aumentou de 1,5 para $2,5 \%$ PV. O NRC (1985) reportou decréscimo de $4 \%$ no NDT para aumento de $1 \%$ no nível de ingestão acima da mantença, ao passo que o NRC (2001) considerou esse decréscimo variável.

A digestibilidade aparente de MS no rúmen não diferiu entre os tratamentos, apresentando média de $73,2 \%$ para as equações conjuntas, valor próximo ao obtido por Rennó (dados não publicados), que encontrou média de $74,2 \%$, em animais submetidos a dietas com inclusão de níveis crescentes de uréia na ração. Este valor foi superior ao de Tibo et al. (2000), de 67,3 , quando forneceram a novilhos dieta com $37,5 \%$ de concentrado. Carvalho et al. (1997) e Ladeira et al. (1999) observaram valores médios de 62,02 e $63,4 \%$, respectivamente, para a digestibilidade ruminal da MS, com aumento dos níveis de concentrado na ração.

O valor médio $(26,8 \%)$ encontrado para a digestibilidade da MS nos intestinos não foi afetado pelos níveis de oferta, sendo semelhante ao observado por Rennó (dados não publicados), que relatou média de $25,8 \%$, porém inferior ao obtido por Dias et al. (2000), de $42,5 \%$.
Os coeficientes de digestibilidades total (DMOTO), ruminal (DMORU) e intestinal (DMOIN) da MO, as equações de regressão (ER) e os respectivos coeficientes de determinação, obtidos para as metodologias de coleta de digesta no abomaso (ABO) e no omaso $(\mathrm{OM})$ e para as duas metodologias em conjunto, em função dos níveis de oferta (NIV), são apresentados na Tabela 6. O teste de identidade de modelos não indicou diferenças entre as metodologias de coleta e, protanto, pode-se recomendar o uso da equação conjunta.

A digestibilidade total da MO apresentou comportamento linear decrescente, em função dos níveis de ingestão, e as digestibilidades ruminal e intestinal total não foram afetadas pelos tratamentos, com médias de 81,6 e $18,4 \%$, respectivamente, para as equações conjuntas. Esses resultados corroboram os obtidos para as digestibilidades da MS.

Merchen et al. (1986) encontraram efeito dos níveis de ingestão alto e baixo, 2,6 e 1,6\% PV, respectivamente, sobre a digestibilidade total da $\mathrm{MO}$ de 78,3 e $81,0 \%$, respectivamente. Woods et al. (1999) também verificaram diferenças significativas para este parâmetro, ao compararem bovinos submetidos a consumo em nível de mantença com aqueles mantidos em regime de duas vezes a mantença.

Tabela 6 - Médias, equações de regressão (ER) e coeficientes de determinação $\left(r^{2}\right)$ para as digestibilidades da matéria orgânica total (DMOTO), no rúmen (DMORU) e nos intestinos (DMOIN), em função dos níveis de oferta (NIV), para as metodologias de coletas no abomaso (ABO) e no omaso (OM)

Table 6 - Means, regression equations (RE) and coefficients of determination ( $\left.r^{2}\right)$ for the total organic matter digestibilities (TOOMD), in the rumen and in the intestines, according to the offer levels (LEV), for the collection methodologies in the abomasum (ABO) and omasum (OM)

\begin{tabular}{|c|c|c|c|c|c|}
\hline \multirow[t]{2}{*}{ Local } & \multicolumn{3}{|c|}{ NIV } & \multirow[t]{2}{*}{ ER } & \multirow[t]{2}{*}{$\mathrm{r}^{2}$} \\
\hline & 1,5 & 2,0 & 2,5 & & \\
\hline \multicolumn{6}{|c|}{ DMOTO } \\
\hline $\mathrm{ABO}$ & 67,6 & 66,8 & 66,4 & $\hat{Y}=69,33-1,183 \mathrm{X}$ & 0,95 \\
\hline $\mathrm{OM}$ & 69,6 & 67,4 & 67,0 & $\hat{Y}=73,04-2,522 \mathrm{X}$ & 0,86 \\
\hline Conjunto (Overall) & 68,6 & 67,1 & 66,7 & $\hat{Y}=71,18-1,852 \mathrm{X}$ & 0,77 \\
\hline \multicolumn{6}{|c|}{ DMORU $^{1}$} \\
\hline $\mathrm{ABO}$ & 81,5 & 81,1 & 81,1 & $\hat{Y}=81,2$ & \\
\hline $\mathrm{OM}$ & 82,1 & 81,9 & 82,1 & $\hat{Y}=82,1$ & \\
\hline Conjunto (Overall) & 81,8 & 81,5 & 81,6 & $\hat{Y}=81,6$ & \\
\hline \multicolumn{6}{|c|}{ DMOIN $^{1}$} \\
\hline $\mathrm{ABO}$ & 18,5 & 18,9 & 18,9 & $\hat{Y}=18,8$ & \\
\hline $\mathrm{OM}$ & 17,9 & 18,1 & 17,9 & $\hat{Y}=18,0$ & \\
\hline Conjunto (Overall) & 18,2 & 18,5 & 18,3 & $\hat{Y}=18,4$ & \\
\hline
\end{tabular}

R. Bras. Zootec., v.33, n.6, p.1604-1615, 2004 
Firkins et al. (1986), em experimento com bovinos ingerindo quantidades diárias fixas de 9,1 e $6,1 \mathrm{~kg}$ MS, não verificaram, como no presente estudo, influência do nível de ingestão sobre a digestibilidade ruminal da MO. Entretanto, Zinn \& Owens (1983) encontraram efeito linear decrescente dos níveis de ingestão utilizados $(1,2 ; 1,5 ; 1,8$ e $2,1 \%$ PV) sobre esta variável.

Resultado próximo aos obtidos no presente trabalho foram relatados por Firkins et al. (1987), em um estudo com novilhos submetidos a níveis de ingestão de 2,1 e $1,4 \%$ PV, observando-se valores de 65,3 e $69,4 \%$, respectivamente, para a digestibilidade total da MO. Para a digestibilidade ruminal desta variável, esses autores obtiveram $69,9 \%$, inferior ao valor médio obtido na presente pesquisa $(81,6 \%)$.

$\mathrm{Na}$ Tabela 7, encontram-se os resultados das digestibilidades total (DPBTO), ruminal (DPBRU) e intestinais (DPBIN) da PB, as equações de regressão (ER) e os respectivos coeficientes de determinação, obtidos para ambas as metodologias de coleta de digesta isoladas e em conjunto, em função dos níveis de ingestão (NIV). O teste de identidade de modelos mostrou haver diferenças entre as digestibilidades totais obtidas nas diferentes metodologias. Para as digestibilidades ruminal e intestinal, o teste de identi- dade de modelos não apresentou efeito do local de amostragem; portanto, pode-se recomendar o uso da equação conjunta para os locais de digestão de proteína. A diferença entre as metodologias para as digestibilidades aparentes totais da PB não apresenta explicação biológica definida, uma vez que os consumos de PB foram semelhantes entre tratamentos e não era esperado efeito sobre a digestão total. Quando se compararam as digestões no rúmen e nos intestinos, não foi observada diferença entre as metodologias.

Aumento do nível de consumo, geralmente, resulta em diminuição na digestibilidade da MS e dos demais nutrientes. $\mathrm{O}$ valor médio $(21,4 \%)$ observado para a digestão ruminal da PB sugere que houve excesso de proteína em relação à energia da dieta. $\mathrm{O}$ valor médio (66\%) obtido para a digestibilidade intestinal da PB pode ser considerado baixo que o da digestibilidade verdadeira da proteína (80\%) citado pelo NRC (1985).

Os resultados das digestibilidades da PB totais apresentaram comportamento linear decrescente, em função dos níveis de oferta (Tabela 7). Woods et al. (1999) verificaram efeito do consumo em nível de mantença e duas vezes a mantença para este parâmetro, indicando comportamento linear decrescente da digestibilidade total da PB com o aumento do nível de ingestão. No entanto, Punia et al. (1988) não

Tabela 7 - Médias, equações de regressão (ER) e coeficientes de determinação $\left(r^{2}\right)$ para as digestibilidades da proteína bruta total (DPBTO), no rúmen (DPBRU) e nos intestinos (DPBIN), em função dos níveis de oferta (NIV), para as metodologias de coletas no abomaso (ABO) e no omaso (OM)

Table 7 - Means, regression equations (RE) and coefficients of determination $\left(r^{2}\right)$ for the total crude protein digestibilities (TOCPD), in the rumen and in the intestines, according to the offer levels (LEV), for the collection methodologies in the abomasum (ABO) and omasum (OM)

\begin{tabular}{|c|c|c|c|c|c|}
\hline \multirow[t]{2}{*}{ Local } & \multicolumn{3}{|c|}{ NIV } & \multirow[t]{2}{*}{ ER } & \multirow[t]{2}{*}{$\mathrm{R}^{2}$} \\
\hline & 1,5 & 2,0 & 2,5 & & \\
\hline \multicolumn{6}{|c|}{ DPBTO } \\
\hline $\mathrm{ABO}$ & 77,6 & 74,2 & 72,4 & $\hat{Y}=84,97-5,119 \mathrm{X}$ & 0,97 \\
\hline $\mathrm{OM}$ & 77,6 & 74,2 & 72,1 & $\hat{Y}=85,5-5,433 \mathrm{X}$ & 0,98 \\
\hline \multicolumn{6}{|c|}{ DPBRU $^{1}$} \\
\hline $\mathrm{ABO}$ & 24,6 & 20,6 & 21,7 & $\hat{Y}=28,0402-2,8891$ & 0,49 \\
\hline $\mathrm{OM}$ & 25,3 & 21,3 & 21,1 & $\hat{Y}=31,0465-4,2324 \mathrm{X}$ & 0,78 \\
\hline Conjunto (Overall) & 25,0 & 21,0 & 21,4 & $\hat{Y}=29,5434-3,5608 \mathrm{X}$ & 0,64 \\
\hline \multicolumn{6}{|c|}{ DPBIN $^{1}$} \\
\hline $\mathrm{ABO}$ & 67,5 & 66,9 & 63,4 & $\hat{Y}=74,0971-4,0755 \mathrm{X}$ & 0,86 \\
\hline $\mathrm{OM}$ & 67,7 & 65,5 & 64,9 & $\hat{Y}=71,7947-2,8822 \mathrm{X}$ & 0,91 \\
\hline Conjunto (Overall) & 67,6 & 66,2 & 64,2 & $\hat{Y}=72,9459-3,4788 \mathrm{X}$ & 0,85 \\
\hline
\end{tabular}

$1 \%$ da quantidade que chega em cada local (\% of the amount that arrives at each compartment). 
encontraram efeito de alta e baixa ingestão sobre esta variável.

Robinson et al. (1985) verificaram redução na digestibilidade ruminal da $\mathrm{PB}$, assim como no presente trabalho, para vacas alimentadas com dietas contendo $65 \%$ de volumoso e submetidas a ingestões crescentes de MS.

Os coeficientes de digestibilidades total (DEETO), ruminal (DEERU) e intestinal (DEEIN) do EE, as equações de regressão (ER) e os respectivos coeficientes de determinação, obtidos para as metodologias de coleta de digesta no abomaso (ABO) e no omaso (OM), e para as duas metodologias em conjunto, em função dos níveis de oferta (NIV), são apresentados na Tabela 8 . O teste de identidade de modelos, realizado para as equações de regressão para as digestibilidades total, ruminal e intestinal total do EE, em função dos níveis de ingestão, não revelou diferenças entre as metodologias de coleta. Portanto, pode-se recomendar o uso da equação conjunta, para avaliar a digestão do EE.

A digestibilidade total do EE não foi influenciada pelos tratamentos e apresentou valor médio de 76,3\% para a equação conjunta, inferior ao obtido por Ítavo (2001), de $80,1 \%$, quando trabalhou com novilhos submetidos a dieta com $40 \%$ de concentrado, e superior ao encontrado por Valadares et al. (1997), de 59,3\%, em estudo com níveis de proteína em dietas para novilhos. Cardoso et al. (2000) observaram efeito linear crescente do nível de concentrado sobre a digestibilidade total do $\mathrm{EE}$, com valor médio de $73,7 \%$.

As digestibilidades ruminal e intestinal total apresentaram comportamento linear crescente e decrescente, respectivamente, em função dos níveis de oferta. Os valores de digestão ruminal do EE negativos indicam síntese ruminal de lipídeos microbianos.

Tibo et al. (2000) e Dias et al. (2000) verificaram aumentos crescentes (valores médios de $-17,9$ e $-24,6 \%$, respectivamente) nas digestibilidades do EE, em função dos níveis de concentrado.

Os valores médios para a digestibilidade intestinal do $\mathrm{EE}$ (entre 74,5 e 80,6\%) foram inferiores aos obtidos por Rennó (dados não publicados) e Sniffen et al. (1992), que encontraram valores médios de 83,2 e $95 \%$, respectivamente.

Tabela 8 - Médias, equações de regressão (ER) e coeficientes de determinação $\left(r^{2}\right)$ para as digestibilidades do extrato etéreo total (DEETO), no rúmen (DEERU) e nos intestinos (DEEIN), em função dos níveis de oferta (NIV), para as metodologias de coletas no abomaso (ABO) e no omaso (OM)

Table 8 - Means, regression equations (RE) and coefficients of determination $\left(r^{2}\right)$ for the total ether extract digestibilities (TOEED), in the rumen (EEDRU) and in the intestines (EEDIN), according to the offer levels (LEV), for the collection methodologies in the abomasum (ABO) and omasum (OM)

\begin{tabular}{|c|c|c|c|c|c|}
\hline \multirow[t]{2}{*}{ Local } & \multicolumn{3}{|c|}{ NIV } & \multirow[t]{2}{*}{$\mathrm{ER}$} & \multirow[t]{2}{*}{$\mathrm{r}^{2}$} \\
\hline & 1,5 & 2,0 & 2,5 & & \\
\hline \multicolumn{6}{|c|}{ DEETO } \\
\hline $\mathrm{ABO}$ & 77,9 & 73,8 & 75,9 & $\hat{Y}=75,9$ & \\
\hline $\mathrm{OM}$ & 77,7 & 78,5 & 74,4 & $\hat{Y}=76,8$ & \\
\hline Conjunto (Overall) & 77,8 & 76,2 & 75,2 & $\hat{Y}=76,3$ & \\
\hline \multicolumn{6}{|c|}{ DEERU $^{1}$} \\
\hline $\mathrm{ABO}$ & $-16,7$ & $-10,6$ & 1,4 & $\hat{Y}=-44,82+18,077 \mathrm{X}$ & 0,97 \\
\hline $\mathrm{OM}$ & $-15,1$ & $-10,6$ & 3,1 & $\hat{Y}=-44,099+18,282 \mathrm{X}$ & 0,92 \\
\hline Conjunto (Overall) & $-15,9$ & $-10,6$ & 2,3 & $\hat{Y}=-44,46+18,18 \mathrm{X}$ & 0,94 \\
\hline \multicolumn{6}{|c|}{ DEEIN $^{1}$} \\
\hline $\mathrm{ABO}$ & 81,0 & 76,3 & 75,4 & $\hat{Y}=88,90-5,661 X$ & 0,87 \\
\hline $\mathrm{OM}$ & 80,1 & 80,5 & 73,5 & $\hat{Y}=91,25-6,622 \mathrm{X}$ & 0,71 \\
\hline Conjunto (Overall) & 80,6 & 78,4 & 74,5 & $\hat{Y}=90,08-6,142 \mathrm{X}$ & 0,76 \\
\hline
\end{tabular}

$1 \%$ da quantidade que chega em cada local (\% amount that arrives to each compartment). 


\section{Conclusões}

A coleta de digesta omasal, via fístula ruminal, pode ser usada para substituir a fistulação no abomaso, tornando o estudo dos locais de digestão um processo menos invasivo.

O teor de NDT diminui com o aumento do nível de oferta de alimento.

\section{Literatura Citada}

AHVENJÄRVI, S.; VANHATALO, A.; HUHTANEN, P. et al. Determination of retículo-rumen and whole-stomach digestion in lactating cows by omasal canal or duodenal sampling. The British Journal of Nutrition, v.83, n.1, p.67-77, 2000.

ASH, R.W. Omasal-abomasal re-entrant cannullae for sheep. Journal Physiology, v.164, 4P, 1962.

BORGES A.L.C.C. Exigências nutricionais de proteína e energia de novilhas das raças Guzerá e Holandesa. Belo Horizonte: Universidade Federal de Minas Gerais, 2000. 90p. Tese (Doutorado em Ciência Animal) - Universidade Federal de Minas Gerais, 2000.

BRANCO, A.F.; MAIA, F.J.; ALCALDE, C.R. et al. Efeitos da fonte de proteína da dieta sobre a digestão parcial e total de amido em bovinos, In: REUNIÃO ANUAL DA SOCIEDADE BRASILEIRA DE ZOOTECNIA, 38., 2001, Piracicaba. Anais... Piracicaba: Sociedade Brasileira de Zootecnia, 2001, p.998-1000.

CARDOSO, R.C.; VALADARES FILHO, S.C.; COELHO DA SILVA, J.F. et al. Consumo e digestibilidades aparentes totais e parciais de rações contendo diferentes níveis de concentrado, em novilhos F1 Limousin x Nelore. Revista Brasileira de Zootecnia, v.29, n.6, p.1832-1843, 2000.

CARVALHO, A.U.; VALADARES FILHO, S.C.; COELHO DA SILVA, J.F. et al. Níveis de concentrados em dietas de zebuínos. 1. Consumo e digestibilidade aparente. Revista Brasileira de Zootecnia, v.26, n.5, p.986-995, 1997.

CONRAD, H.R.; PRATT, A.D.; HIBBS, J.W. Regulation of feed intake in dairy cows.1, Change in importance of physical and physiological factors with increasing digestibility, Journal of Dairy Science, v.47, n.1, p.54-62, 1964.

DIAS, H.L.C.; VALADARES FILHO, S.C.; COELHO DA SILVA, J.F. et al. Consumo e digestões totais e parciais em novilhos $F_{1}$ Limousin $x$ Nelore alimentados com dietas contendo cinco níveis de concentrado. Revista Brasileira de Zootecnia, v.29, n.2, p.545-554, 2000.

FIRKINS, J.L.L.; BERGER, L.L.; MERCHEN, N.R. et al. Effects of feed intake and protein degradability on ruminal characteristics and site of digestion in steers. Journal of Dairy Science, v.69, n.8, p.2111-2123, 1986.

FIRKINS, J.L.; LEWIS, S.M.; MONGOMERY, L. et al. Effects of feed intake and dietary urea concentration on ruminal dilution rate and efficiency of bacterial growth in steers. Journal of Dairy Science, v.70, n.11, p.2312-2321, 1987.

FORBES, J.M. Voluntary food intake and diet selection in farm animals. Wallingford: CAB International, 1995. 532p.

HUHTANEN, P.G.; BROTZ, P.G.; SATTER, L.D. Omasal sampling technique for assessing fermentative digestion in the forestomach of dairy cows. Journal of Animal Science, v.75, n.5, p.1380-1392, 1997.
ITAVO L.C.V. Consumo, digestibilidade e eficiência microbiana de novilhos alimentados com dietas contendo vários níveis de concentrado, utilizando diferentes indicadores e períodos de coleta. Viçosa, MG: Universidade Federal de Viçosa, 2001 100p. Tese (Doutorado em Zootecnia) - Universidade Federal de Viçosa, 2001.

LADEIRA, M.M.; VALADARES FILHO, S.C.; COELHO DA SILVA, J.F. et al. Consumo e digestibilidades aparentes totais e parciais de dietas contendo diferentes níveis de concentrado, em novilhos Nelore. Revista Brasileira de Zootecnia, v.28, n.2, p.395-403, 1999.

LLAMAS-LAMAS, G.; COMBS, D.K. Effects of forage to concentrate ratio and intake level on utilization of early vegetative alfalfa silage by dairy cows. Journal of Dairy Science, v.74, n.2, p. 526-536, 1991.

MERCHEN, N.R.; FIRKINS, J.L.; BERGER, L.L. Effects of intake and forage on ruminal turnover rates, bacterial protein synthesis and duodenal amino acid flows in sheep. Journal of Animal Science, v.62, n.1, p.216-223, 1986.

MERTENS, D.R. Regulation of forage intake. In: FAHEY Jr., G.C. (Ed) Forage quality, evaluation and utilization. Madison: American Society of Agronomy, 1994. p.450-493.

NATIONAL RESEARCH COUNCIL - NRC. Ruminant nitrogen usage. Washington, D.C.: National Academy of Science, 1985. 158p.

NATIONAL RESEARCH COUNCIL - NRC. Nutrient requirements of dairy cattle. 6.ed. Washington D.C.: National Academy of Science, 1989. 158p.

NATIONAL RESEARCH COUNCIL - NRC. Nutrient requirements of beef cattle. 7.ed. Washington, D.C.: National Academy of Science, 1996. 242p.

NATIONAL RESEARCH COUNCIL - NRC. Nutrient requirements of dairy cattle. 7.ed.rev. Washington, D.C.: National Academic Press, 2001. 381p.

PUNIA, B.S.; LEIBHOLZ, J.; FAICHNEY, G. Effects of level of intake and urea supplementation of alkali-treated straw on protozoal and bacterial nitrogen synthesis in the rumen and partition of digestion in cattle. American Journal Agricultural Research, v.39, n.1, p.1181-1194, 1988.

REGAZZI, J.A. Teste para verificar a identidade de modelos de regressão. Pesquisa Agropecuária Brasileira, v.31, n.1, p.1-17, 1996

ROBINSON, P.H.; SNIFFEN, C.J.; Van SOEST, P.J. Influence of level of feed intake on digestion and bacterial yield in the forestomachs of dairy cattle. Canadian Journal of Animal Science, v.65, p.437-445, 1985.

RUPP, G.P.; KREIKEMEIER, K.K.; PERINO, L.J. et al. Measurement of volatile fatty acid disappearance and fluid flux across the abomasum of cattle utilizing an improved omasal cannulation technique. American Journal of Veterinary Research, v.55, n.4, p.522-529,1994.

SILVA, D.J. Análise de alimentos (Métodos químicos e biológicos). Viçosa, MG: Universidade Federal de Viçosa, 1990. 165p.

SILVA, F.F. Desempenho, características de carcaça, composição corporal e exigências nutricionais (energia, proteína, aminoácidos e macrominerais) de novilhos Nelore nas fases de recria e engorda recebendo diferentes níveis de concentrado e proteína. Viçosa, MG: Universidade Federal de Viçosa, 2001. 211p. Tese (Doutorado em Zootecnia) Universidade Federal de Viçosa, 2001.

SNIFFEN, C.J.; BEVERLY, R.W.; MOONEY, C.S. Nutrient requirement versus supply in dairy cow: strategies to account

R. Bras. Zootec., v.33, n.6, p.1604-1615, 2004 
for variability. Journal of Dairy Science, v.76, n.10, p.3160-3178, 1993.

SNIFFEN, C.J.; O‘CONNOR, J.D.; Van SOEST, P.J. et al. A net carbohydrate and protein system for evaluation cattle diets: II. Carbohydrate and protein availability. Journal of Animal Science, v.70, n.11, p.3562-3577, 1992.

TIBO, G.C.; VALADARES FILHO, S.C.; VALADARES, R.F.D. et al. Níveis de concentrado em dietas de novilhos mestiços F1 Simental x Nelore 1. Consumo e digestibilidades. Revista Brasileira de Zootecnia, v.29, n.3, p.910-919, 2000.

TITGEMEYER, E.C. Design and interpretation of nutrient digestion studies. Journal of Animal Science, v.75, n.8, p.2235-2247, 1997.

TYRREL, H.F.; MOE, P.W. Effect of intake on digestive efficiency. Journal of Dairy Science, v.58, n.8, p.1151-1163, 1975.

UNIVERSIDADE FEDERAL DE VIÇOSA - UFV. Sistema de análises estatísticas e genéticas - SAEG. Viçosa, MG: Universidade Federal de Viçosa, 1999. (Apostila)
VALADARES, R.F.D.; GONÇALVES, L.C.; SAMPAIO, I.B. et al. Níveis de proteína em dietas de bovinos. 1. Consumo e digestibilidades aparentes totais e parciais. Revista Brasileira de Zootecnia, v.26, n.6, p.1252-1258, 1997.

Van SOEST, P.J. Nutritional ecology of the ruminants. 2.ed. Ithaca: Cornell University, 1994. 476p.

WOODS, V.W.; MOLONEY, A.P.; MULLIGAN F.J. et al. The effect of animal species (cattle or sheep) and level of intake by cattle on in vivo digestibility of concentrate ingredients. Animal Feed Science and Technology, v.80, n.1, p.35$190,1999$.

ZINN, R.A.; OWENS, F.N. Influence of feed intake level on site of digestion in steers fed a high concentrate diet. Journal of Animal Science, v.56, n.2, p.471-475, 1983.

Recebido em: 28/06/02

Aceito em: 09/09/03 